\title{
Example of development of production schedule in the reorganization of residential areas
}

\author{
German Dzhusoev ${ }^{1}$, Sergey Sinenko ${ }^{1, *}$, Alexey Slavin ${ }^{1}$ \\ ${ }^{1}$ Moscow State University of Civil Engineering, 26, Yaroslavskoe Shosse, 129337, Moscow, Russia
}

\begin{abstract}
Reducing production in case of significant problems with production capacity is not a popular solution for many managers, but the benefits of such a solution may be unexpected. Firstly, the economic performance of production can be really improved because the reduction of work intensity eliminates clutter and disorder in the work centers, which led to additional costs. Secondly, the quality of work (and, as a consequence, the convenience of further recycling or reuse in the case of demolition) may improve, as in a normal environment it will be given more attention. Perhaps the solution Manager can be an organization overtime or events of a technical nature, which, however, do not always have the desired flexibility. Redistribution of the flow to other work centers is provided as a result of solving the assignment problem.
\end{abstract}

\section{Introduction}

Development of production schedules completes the process, which includes the development of a business plan, aggregate planning, preparation of the master planproduction schedule and MRP-procedure. Schedules detail the plans of the top level, bringing them to specific performers and breaking into short-term assignments for change, day, hour. Development of production schedules is one of the most difficult tasks of production (operational) management. At the lower level of management, there are many disturbing external and internal factors, and the requirements for the efficiency of decision-making and execution of management decisions are strict. At the same time, usually performed simultaneously is at different stages of readiness of many orders, the completion time of each of which is different. If in the management of production capacities the problem is reduced to overcoming the uncertainty of the level of demand, then at the lower level the manager deals with the uncertainty of demand in time.

\section{Methods}

The production schedule represents a breakdown of the actions required for implementation of the plans, in time, capturing the moments of their beginning and end and defining their execution order. The nature of the scheduling problem faced by managers is largely determined by the structure of the operating system and the objectives to be achieved. Within

\footnotetext{
* Corresponding author: sasin50@mail.ru
} 
the given limits (what can be done in the production system and what should be done), the Manager solves the task of scheduling. At the same time, he must first decide which principle approach should be used in developing the schedule, then determine the necessary procedures for this activity, first of all - the procedure for linking schedules and production capacities.

Reverse the schedule. This is a typical example of a schedule that is externally oriented to the completion date. A serious problem here is the assessment of the duration of individual work (operations), as well as waiting time in line due to the employment of the next operation. Along with the obvious negative result of such expectations (the scheduling becomes more complicated), there are also its positive aspects. In the conditions of some internal uncertainty (duration of work, efficiency of equipment, etc.), the presence of queues for work allows more efficient use of the internal resources of the system. In other words, the presence of internal uncertainty in the system relatively worsens the chance to execute processes on time, but improves the use of its own resources. Such schedules are usually presented in the form of Gantt schedules, where the time axis is applied to the straight segments, the length of which is proportional to the duration of the relevant work (operations). These charts are named for Henry Gantt, who developed the concept of their construction in the late nineteenth century, Such charts visual. They show what jobs or departments are involved and when they are involved in the process. The lack of them - it's not visible dependencies between operations.

The schedule being developed ahead. The procedure for developing such a schedule would be actually the opposite of that considered in the previous subsection. The schedule thus is internally oriented and is made generally counting on determination of the beginning of accomplishment of all works (operations).

The order of execution. The sequence search procedure is used to determine the optimal order in which demolition sites are passed through a sequence of processing or servicing devices. In the case of a production system, the task is formulated more traditionally: it is necessary to find the optimal order of demolition in the areas where they are carried out some sequence of operations. And in General it can be both subject-closed, and a technological site.

There are two cases of solving the problem - static and dynamic. A static case where all the tasks for which the schedule is created are known and their list is not updated during their execution in the system. That is, there is no receipt of jobs in the system or incoming jobs are queued and wait for the next cycle of the problem. The dynamic case, which allows for the admission of jobs into the system and prompt their inclusion in the procedure of scheduling. It is obvious that in such a situation, the task of determining the priority should be solved again every time a new task enters the system. The information necessary to solve this problem is the time spent by each processing or servicing device for processing (servicing) of each task (client), as well as the sequence of their passage through these devices.

In the static case of solving the problem, the goal is usually to minimize the total time of execution of all tasks, i.e. to maximize the throughput of the system. This formulation of the problem is more typical for internally oriented schedules. The solution of the problem allows more efficient use of resources, and in the case of a production system - equipment, primarily expensive or limiting the throughput of the process. This means that this goal will dominate for the limiting equipment, even if the Manager decides to build an externally oriented schedule as a whole. In the dynamic case, the predominant goal is to complete each task by a certain date or to minimize the total waiting time of tasks in the queue, which is more typical for drawing up externally oriented schedules. This goal can be set in a static case. Table 1 presents a comprehensive analysis of the possibilities of using the basic methods of scheduling.

The problem of prioritization in a static statement with a minimum total cycle duration criterion has four main variants (the first three variants are widely known from practice): 
1) n tasks must pass in the same order two work centers;

2) $n$ tasks must pass in the same order three work centers;

3) $n$ tasks must pass in the same order $t$ work centers;

4) two jobs must pass in an arbitrary sequence of $t$ jobs.

Table 1. Basic methods of drawing up of production schedules.

\begin{tabular}{|c|c|c|c|c|c|}
\hline \multirow[b]{2}{*}{$\begin{array}{l}\text { The method of } \\
\text { scheduling }\end{array}$} & \multirow[b]{2}{*}{ Brief description of the methodology } & \multicolumn{4}{|c|}{ Production } \\
\hline & & 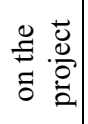 & $\begin{array}{l}\dot{\overline{0}} \\
\overline{\tilde{o}} \\
\tilde{0}\end{array}$ & $\stackrel{n}{\stackrel{0}{0}}$ & 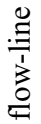 \\
\hline $\begin{array}{l}\text { 1. Reverse the } \\
\text { schedule (Gantt } \\
\text { charts) }\end{array}$ & $\begin{array}{l}\text { The schedule of the set of works required to meet the } \\
\text { demand is modeled as straight segments on the time } \\
\text { axis in the opposite direction from the completion date }\end{array}$ & + & + & + & \\
\hline $\begin{array}{c}\text { 2. Schedule, } \\
\text { developed } \\
\text { forward (Gantt } \\
\text { charts) }\end{array}$ & $\begin{array}{l}\text { Opposite to the reverse schedule, when modeling is } \\
\text { carried out forward from the specified date to get the } \\
\text { completion date of the aggregate work }\end{array}$ & + & + & + & \\
\hline $\begin{array}{l}\text { 3. Priority of } \\
\text { implementation }\end{array}$ & $\begin{array}{l}\text { Determination of the best order of passing a given set } \\
\text { of works through a given sequence of jobs in order to } \\
\text { minimize the total time of work, waiting in line, } \\
\text { downtime, etc. }\end{array}$ & + & + & + & \\
\hline 4. Dispatching & $\begin{array}{l}\text { Determine the best order of skipping a given set of } \\
\text { activities across a single work center using a set of } \\
\text { priority rules }\end{array}$ & & + & + & + \\
\hline 5. Appointments & $\begin{array}{l}\text { Pinning resources from the set available for each of the } \\
\text { activities to be performed (and the work can use more } \\
\text { than one resource with different efficiency), in order to } \\
\text { optimize the total use of resources }\end{array}$ & ? & + & + & \\
\hline $\begin{array}{l}\text { 6. Schedule } \\
\text { (schedule, } \\
\text { standard-plan) }\end{array}$ & $\begin{array}{c}\text { Schedules and schedules determine when specific } \\
\text { work centers or other resources are available for those } \\
\text { who want to use them }\end{array}$ & + & + & + & + \\
\hline $\begin{array}{l}\text { 7. Optimized } \\
\text { production } \\
\text { technology } \\
(\mathrm{OPT})\end{array}$ & $\begin{array}{c}\text { Scheduling of material flow through the" bottleneck " } \\
\text { of the process }\end{array}$ & ? & $?$ & + & + \\
\hline $\begin{array}{l}\text { 8. Planning the } \\
\text { requirements for } \\
\text { the components } \\
\text { of the products }\end{array}$ & $\begin{array}{c}\text { Similar to the reverse schedule, it is used for batch } \\
\text { production planning and affects inventory and capacity } \\
\text { management }\end{array}$ & $?$ & + & + & \\
\hline $\begin{array}{l}\text { 9. Enterprise } \\
\text { resource } \\
\text { planning (ERP } \\
\text { II) }\end{array}$ & $\begin{array}{l}\text { Development of the previous approach, but on a } \\
\text { broader conceptual basis }\end{array}$ & $?$ & + & + & \\
\hline $\begin{array}{l}\text { 10. Network } \\
\text { analysis (critical } \\
\text { path method) }\end{array}$ & $\begin{array}{c}\text { Used similarly to the forward and reverse timesheet, } \\
\text { but can display more complex logical relationships and } \\
\text { interrelations between activities that need to be } \\
\text { performed as part of a project; opens up more } \\
\text { modeling possibilities }\end{array}$ & + & + & $?$ & \\
\hline
\end{tabular}

\section{Results}

The first option has a simple and effective solution, which is called by the name of its Creator algorithm (method) Johnson. The second option can also be reduced under certain conditions 
to a solution by Johnson's method, but the result will not necessarily be optimal. A rigorous solution to this problem was given by R. Bellman, but it is labor intensive. The third option is the most difficult. An effective heuristic procedure for its resolution is known as the CDS algorithm. This algorithm extends Johnson's method to the General case of the problem statement and provides a near-optimal solution. There are other approaches that use the theory of queues and computer modeling to solve this problem. But all of them are timeconsuming and complex and at the same time do not guarantee the optimal sequence.

Table 2. Order and time of passage of workplaces.

\begin{tabular}{|c|c|c|c|c|}
\hline \multirow{2}{*}{$\begin{array}{l}\text { No. works } \\
\text { PP }\end{array}$} & \multicolumn{2}{|c|}{ The first task } & \multicolumn{2}{|c|}{ Second task } \\
\hline & $\begin{array}{c}\text { The procedure for } \\
\text { passing }\end{array}$ & Time of work, units. & $\begin{array}{c}\text { The procedure for } \\
\text { passing }\end{array}$ & $\begin{array}{c}\text { Time of work, } \\
\text { units. }\end{array}$ \\
\hline 1 & A & 4 & A & 2 \\
\hline 2 & B & 3 & $\mathrm{D}$ & 2 \\
\hline 3 & $\mathrm{C}$ & 1 & $\mathrm{C}$ & 4 \\
\hline 4 & $\mathrm{D}$ & 3 & B & 2 \\
\hline 5 & $E$ & 2 & $E$ & 2 \\
\hline & Total & 13 & Total & 12 \\
\hline
\end{tabular}

The basic rule of motion that model the system state at each moment of time the following. Simultaneous execution at different jobs, relating to both jobs, means synchronous forward movement on both axes of time $\mathrm{X}$ and $\mathrm{Y}$, ie the movement of the point along the bisector of the right angle at the base of the coordinate axes (at an angle of $45^{\circ}$ to any of the axes). This mode of point movement (system operation) is most rational. If there is a shaded rectangle on the point path, it can only pass through one of its sides, because any piece of equipment can only do one job for the time shown in the figure by the area of the corresponding rectangle. At this time, the job that corresponds to the other side of the rectangle is not running - it is Queuing. The search for a solution is empirical.

Note that even if the simplest approaches do not lead to optimal solutions, their use in practice is always desirable, because any ordering is always accompanied by a positive effect. In this sense attract the attention of the developments of Russian scientists S. A. Sokolichin and V. A. Petrov, dedicated to solving problems of priority. From a practical point of view, their effectiveness is significantly higher than with other simple rules and at the same time the procedures they offer are simpler than the SDO algorithm. The rules, developed by V. A. Petrov, and S. A. By socalizing available for use by managers and drafters of the scheduling at the shop level. The fourth variant of the problem solution is considered in the example.

Let there are five jobs A, B, C, D and E and two of the task order and the passage of time which of these jobs is shown in table. 2. The solution of the problem is illustrated in Fig. 23.1. On it, the run time of the specified job sequence 1 is plotted on the $X$ - axis, and the job 2 is plotted on the $y$-axis.the point with coordinates $(0,0)$ indicates the start of maintenance, and the point $(13,12)$ indicates completion. The task is to find the shortest path from the start point to the end point of service.

Figure 1 shows that the problem has two acceptable solutions, the best of which gives the total execution time of both jobs, 15 units of the Appropriate schedule of assignments is shown in Figure. 2.

Dispatching. The various approaches described above suggest methods for finding the best way to perform a sequence of tasks. However, one has to wonder whether the pursuit of the optimum as a result of running too much calculations? In addition, all the methods only deal with static staging and the goal is to maximize system throughput. When there is a need to take into account the dynamics or precise timing of completion of works, acceptable General approaches to optimization are absent. 
In both cases, it makes sense to consider the possibility of solving such problems in the simplified terms of scheduling. We are talking about the task of finding the priorities of assigning work to one workplace, instead of trying to accurately schedule their implementation on a sequence of jobs. The effectiveness of dispatching is determined by the mass of its application. It finds particularly wide application in the complex (along the routes of traffic flow) discrete production processes. The essence of the dispatch procedure is to use priority rules when scheduling work by a single work center. Moreover, the work center can be understood not only one workplace, but also the site. In the case of planning the work of the site, when the tasks being run are the essence of the sequence of works, it is actually proposed to replace the methods considered before dispatching methods for determining the optimal sequence of execution of the sequence of works. Such a replacement should be treated with caution and only with a view to dramatically simplifying the process of finding an acceptable solution.

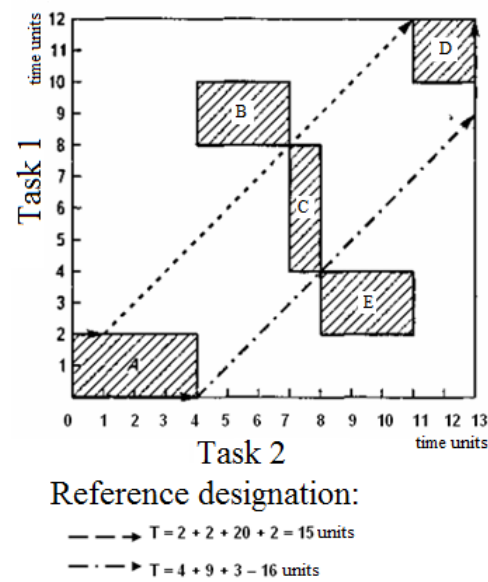

Fig. 1. Scheme illustrating the solution of the problem.

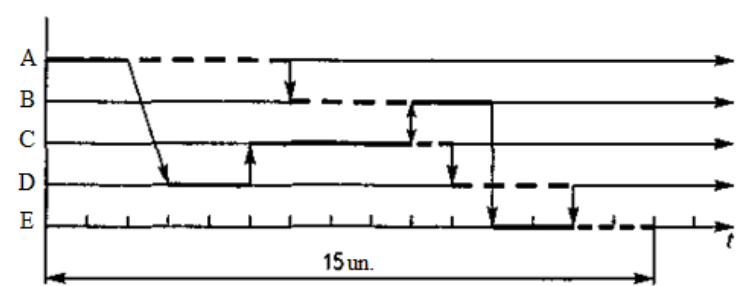

Convention:

- - - - Schedule of the first task Schedule of the second task

Fig. 2. The schedule of passing by two tasks of sequences of work centers: the best option (Gantt schedule).

In the case of line scheduling, priority rules only work when the line changeover time is close to any new batch from any previous batch. There are a lot of priority rules, let's consider only the most significant and applicable ones.

Rule 1. Gives priority to works (tasks) with minimum "free time", i.e. the time remaining before the planned term of completion of all sequence of works taking into account total duration of performance of their still remaining outstanding part:

$$
S=t_{p l}-t_{o}-\sum_{j} t_{j}
$$

where $t_{\mathrm{pl}}$ - planned date of completion of work / task (sequence of works);

$\mathrm{t}_{\mathrm{o}}$ - current date;

$\sum_{j} t_{j}$ - duration of work / total remaining duration of all work/until completion of the task.

Rule 2. Gives priority to works (tasks) with a minimum "free time coefficient", i.e.S $/\left(t_{p l}-t_{o}\right)$. In this, as in the first case, if the priority index is negative, the job/task cannot be completed by the planned date.

Rule 3. Gives priority to works (tasks) with a minimum "critical ratio", i.e. the ratio of the time remaining until the completion of the work/task to the time of all work before the 
completion of the task: $\left(t_{p l}-t_{o}\right) / \sum_{j} t_{j}$. In this case, work/tasks with a critical ratio, less than one, are lagging behind and require a first run.

Rule 4. Gives priority to jobs with minimal lead time. We can also talk about tasks here. Then the priority is given to the task with the minimum amount.

Rule 5. Gives priority to works (tasks) with the maximum execution time, i.e. opposite to the previous rule.

Rule 6. Gives priority to works (tasks) with the earliest completion date of the $t_{\mathrm{pl}}$.

Rule 7. "The first came - the first served" (first in - first out, FIFO). This rule is used both independently and in addition to other rules, when there are identical values of the index of priority of work (tasks).

Priority rules can be classified according to different criteria (Fig. 3).

A large number of studies have been carried out and queue models have been developed to determine the best priority rules. They were evaluated on the basis of two types of indicators: completion of work (task) by the specified date; system throughput estimates.

The first type of indicators is based mainly on the analysis of the relative frequency with which the modeling work was completed later than the specified period. Most of all, the effectiveness of the rule characterizes the average delay in the completion of work, as well as the number of late works. The second type includes indicators such as the average number of jobs in the queue to run, the average waiting time in the queue, and the average number of jobs in the system. The analysis showed that rule 4 and a significant number of its modifications were the best for most criteria. The practical application of priority rules is discussed in detail in the literature.

\section{Discussion}

The criterion of the shortest duration of work is usually the best when maximizing throughput or minimizing the average number of jobs in the system. Its main disadvantage is that long lasting work will always move back, subject to the priority of the short-term. Criterion" the first came - the first served " does not give a gain on the majority of indicators. However, it has the advantage of fairness to the user, which is important in service systems. The method of critical attitude, as a rule, gives good results in terms of the average time delay of works.

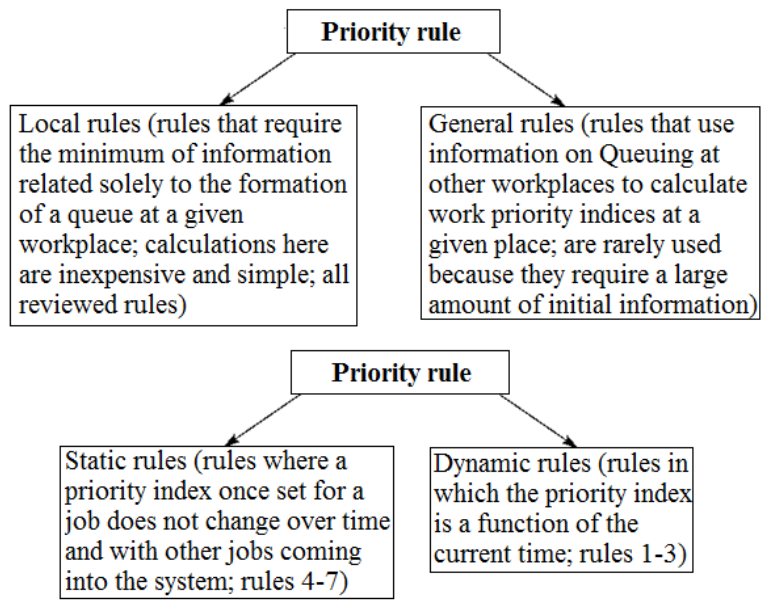

Fig. 3. Classification of priority rules when dispatching.

Appointments. The method of assignment of works to various interchangeable work centers, characterized by different efficiency of their implementation, is widely known and 
is widely used in practice. It allows you to get the optimal distribution of the most intense work across multiple work centers and thereby increase the throughput of the system. The task of operations assignment is solved by the transport method of linear programming.

Optimized production technology. Optimized production technology (OPT) is a computer package that helps to paint the movement of batch flows through production systems. The purpose of scheduling is to maximize system output or throughput. The principal distinguishing feature of the OPT approach is its focus on actions to embroider "bottlenecks" of the system that limit its capacity. The OPT system is based on a set of rules that have a fairly broad meaning and can be used in scheduling under appropriate conditions. Thus, the OPT approach can be called a system of planning, scheduling and inventory management techniques. The rules of scheduling, proclaimed OPT approach, are presented in the table. 3 .

System MRP and MRP II. The result of the MRR procedure is a schedule of works with an indication of their priorities. Since at the top level of planning the production capacity is considered only in the enlarged meters, and the schedules developed by the MRP procedure are sufficiently detailed, the question arises of a detailed analysis of the capacity. This task is solved by the MRPII system - a tool for analyzing the capacity of the operating system units in the process of scheduling. In case of discrepancy between the available capacity of individual elements of the production system and the incoming production orders in the system generated current backlogs.

Table 3. Rules for scheduling in accordance with the OPT approach.

\begin{tabular}{|c|l|}
\hline № & \multicolumn{1}{|c|}{ OPT- rules } \\
\hline 1 & Balance should be streams, not power \\
\hline 2 & $\begin{array}{l}\text { The level of use of work centers that are not a bottleneck of the system is not determined by } \\
\text { their own potential, but depends on other constraints in the system }\end{array}$ \\
\hline 3 & The implementation and use of a resource are not synonymous \\
\hline 4 & An hour lost in a "narrow place", is an hour lost for the entire system \\
\hline 5 & An hour saved not in a "tight spot" is a Mirage \\
\hline 6 & Bottlenecks control the speed of production flows and the level of inventories \\
\hline 7 & The size of the transport batch can not be equivalent to operating the party \\
\hline 8 & The plot size must be variable \\
\hline 9 & $\begin{array}{l}\text { The production capacity (throughput) and priority of demolition processes should be } \\
\text { considered simultaneously rather than sequentially }\end{array}$ \\
\hline 10 & $\begin{array}{l}\text { The plot-to-plot timetable should be based on taking into account all system constraints at the } \\
\text { same time. The leading time (time of execution of processes on the site) should be the result } \\
\text { of scheduling and can not be predetermined in advance }\end{array}$ \\
\hline
\end{tabular}

To monitor compliance MRPII procedure called "control input—output". This routine checks the load of each work center capacity using the boot Gantt charts. Insufficient control of the power and condition of the working center is the reason reducing the efficiency of the material flow through it. If orders are received in the work center is faster than prescribed in the plan, then, at the entrance of the growing backlog, there are problems with the quality. If jobs arrive at a slower rate, the work center is underloaded, and later may even go off schedule, and disrupt the plan execution. "Input-output" is the technique of allowing the Manager the flexibility to manage workflows. At the same time it is available the following tools:

1) correction of the normative data on the production capacity of the work centre and return plan on the upper level of management for improvement with regard to these data;

2 ) increase the capacity of installed equipment and/or installation of additional equipment (in the long term);

3) reallocation of the flow in time within a given work center or in space to other work centers. 


\section{Conclusions}

Reducing production in case of significant problems with production capacity is not a popular solution for many managers, but the benefits of such a solution may be unexpected. Firstly, the economic performance of production can be really improved because the reduction of work intensity eliminates clutter and disorder in the work centers, which led to additional costs. Secondly, the quality of work (and, as a consequence, the convenience of further recycling or reuse in the case of demolition) may improve, as in a normal environment it will be given more attention. Perhaps the solution Manager can be an organization overtime or events of a technical nature, which, however, do not always have the desired flexibility. Redistribution of the flow to other work centers is provided as a result of solving the assignment problem.

\section{References}

1. A.A. Afanasiev, E.P. Matveev, Reconstruction of residential buildings. Part I. Technology restoration of operational reliability of residential buildings (Moscow, 2008)

2. K.I. Bashlai, V.Ya. Gendin, N.I. Evdokimov, B.V. Zhadanovsky, The builder's builder. Concrete and reinforced concrete works (Moscow, 1980)

3. S.N. Bulgakov, Reconstruction of residential houses of the first mass series and low-rise residential development (Moscow, 2001)

4. P.G. Grabovyi, Reconstruction and renovation of the existing building of the city (Moscow, 2006)

5. V.V. Guryev, Industrial and civil construction 12 (2008)

6. M.N. Ershov, The system method of reconstruction of buildings in operation mode: diss. Cand. tech. (MSUCE, 2005)

7. B.V. Zhadanovsky, Industrial and civil construction 10 (2009)

8. Russian Standatd SP 48.13330.2011

9. Russian Standatd SP 7013330 (2011)

10. N.N. Danilova, O.M. Terentyev, Technology of building processes (Moscow, 2000)

11. Federal Law of 23.11.2009, No. 261-FZ (2009)

12. B.V. Zhadanovsky, A.V. Beschastyi, Mechanical processing of diamond tools by nonmetallic materials and reinforced concrete in construction (Moscow, 2017)

13. X. Gu, X. Jin, Y. Zhou, Basic Principles of Concrete Structures (2016)

14. W. Kurdowski, Cement and Concrete Chemistry (2014)

15. M.N. Fardis, Innovative Materials and Techniques in Concrete Construction (2012)

16. J. Xiao, Recycled Aggregate Concrete Structures (2018)

17. M. Setareh, Concrete Structures (2017)

18. P.P. Oleynik, V.I. Brodsky, Industrial and Civil Engineering 3 (2017)

19. P.P. Oleynik, T.K. Kuzmina, News of higher educational institutions, technology of textile industry $\mathbf{3}$ (2017)

20. S.A. Sinenko, B.V. Zhadanovsky, A.Yu. Slavina, Bulletin of Construction Equipment 4 (2018) 